\title{
Comparison of Verbal and Non-Verbal Communication Between Deaf Children with no Cochlear Implantation and Deaf Children 12-24 Months After Cochlear Implantation
}

\author{
Nahid Jalilevand ${ }^{1 *}$, Mona Ebrahimipour ${ }^{2}$, Masoud Motasaddi Zarandi ${ }^{3}$, Mohamad Kamali ${ }^{4}$, Leyla Fayazi ${ }^{5}$ \\ 1. PhD, Department of Speech Therapy, School of Rehabilitation Sciences, Iran University of Medical Sciences, Tehran, \\ Iran \\ 2. PhD, Department of Speech Therapy, University of Social Welfare and Rehabilitation Sciences, Tehran, Iran \\ 3. PhD, .Department of Otolaryngology, Tehran University of Medical Sciences, Tehran, Iran \\ 4. PhD, Department of Rehabilitation Management, School of Rehabilitation Sciences, Iran University of Medical Sci- \\ ences, Tehran, Iran \\ 5. PhD Student in Linguistics, Department of Speech \& Language Pathology, Special Education Organization, Tehran, \\ Iran
}

\begin{tabular}{c} 
Article Info \\
\hline Received: 2018/07/29 \\
Accepted: 2018/10/06 \\
Published Online: 2018/12/15 \\
DOI: 10.30699/fdisj.1.3.1 \\
How to Cite This Article \\
Jalilevand N., Ebrahim- \\
pour M., Motasaddi Zarandi \\
M., Kamali M., Fayazi L. \\
Comparison of Verbal and \\
Non-Verbal Communication \\
Between Deaf Children with \\
no Cochlear Implantation and \\
Deaf Children 12-24 Months \\
After Cochlear Implantation. \\
Function and Disability Jour- \\
nal. 2018 (Automn) Vol 1. No \\
4. Pages: 1-7.
\end{tabular}

Use your device to scan and read the article online

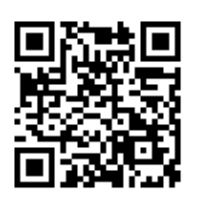

\section{ABSTRACT}

Background and Objectives: It has been shown that cochlear implant significantly improves verbal communication in deaf children. The aim of the current study was to investigate and compare the verbal and non-verbal communication abilities in two groups of deaf children: without cochlear implant (CI), and children using CI for 1224 months. The results were then compared with typically-developing children as the control group.

Methods: 87 children participated in this cross-sectional, descriptive analytical study, (14 deaf children without CI, 25 children with CI that their hearing ages were 12 to 24 months and 48 normal children aged 12 to 24 months). A reliable verbal and non-verbal checklist was completed by parents and nonparametric method was used for data analyzing.

Results: The results indicated that non-verbal communication skills were similar in all groups with no significant difference $(P>0.05)$. However, verbal abilities in deaf children without $\mathrm{CI}$ were significantly impaired compared to the children with $\mathrm{CI}$ and control group $(P<0.05)$. Furthermore, there was no significant difference between the verbal communication scores of children with $C I$ and normal children $(P>0.05)$.

Conclusion: It can be expected that deaf children who receive CI, will reach the verbal communication abilities of 12-24-month-old typically children, at least 12 to 24 months post-implantation

Keywords: Non-Verbal and verbal communication, Deaf children, Cochlear implantation, Typically-Developing children

\section{Introduction}

Speech and language delays which can adversely affect every aspect of children's lives are the most reported problems in children and often the first concerns expressed by parents (Wetherby and Prizant, 1996). Parents usually notice these problems by comparing their child's communicative behavior with other children ( Huttunen and Välimaa, 2010). One of the key criteria in prescribing cochlear implantation for deaf children is whether they experience any spoken language difficulties or not (Budenz et al., 2013). Several studies have shown that receptive and expressive oral language will be improved after the CI surgery (Peterson et al., 2010); however, the early intervention is one of the most important determinant factors of $\mathrm{CI}$ in language learning (Robins et al., 1997). The authors sug- 
gested that children between 2 and 5 years of age were able to learn oral language better than children above 5 years old (Fryauf-Bertschy et al., 1997; Wang et al., 2007). Holt and Svirsky concluded that the rate of language development in children who were implanted after 2 years old was slower than those who were implanted under that age ( Holt and Svirsky, 2008).

The assessment tools are essential for measuring speech and language outcomes after the cochlear implantation. Valid and reliable tools are required for precise measurement. Parents are usually the most knowledgeable individuals about their child's communication skills, and their report is often more reliable than the professional's observations. One of the tools that can provide valuable information about the child's language abilities is the parent questionnaire. The parent reporting is specifically helpful for acquiring data on early language development, especially between the ages 12-30 months, and it can provide such valuable information which cannot be accessed otherwise (Dale , 1991). There are some studies based on the exploring of CI outcomes. The views of parents on CI and the parents' expectation from children using CI, was based on the parent questionnaire (Kumar et al., 2013; Kumar et al., 2017; Archbold et al., 2008). In these studies, parents completed the questionnaire and their responses were analyzed. They had reported improvement in the communication and spoken language within the family. Nikopoulos et al. analyzed the views of parents on CI. They asked parents to complete a questionnaire including 3 domains (communication, listening and development of speech and language). The results showed parents satisfaction of the outcome of CI (Nikolopoulos et al., 2001).

May - Mederake studied verbal language based on a parent questionnaire and indicated that children who had passed their implantation for 24 months showed no significant difference compared to the normal 24-month-old children in oral language ( May - Mederake, 2012).

The purpose of the present study was to examine the verbal and non-verbal communication abilities in two groups of deaf children: children without CI and chil- dren who had up to 24 months of implant experience. Since most of the Iranian deaf children are not implanted under 2 years of age, we want to answer this question that: how much is the least improved verbal abilities of deaf children who use a cochlear implant for at least 24 months.

\section{Materials and Methods}

This cross-sectional study was conducted on 87 monolingual Persian-speaking children (45 girls and 42 boys). They were divided into two groups; deaf and normal hearing children. The deaf group included 39 children with and without CI (14 deaf children without CI aged 12-24 months and 25 children with unilateral CI after 12-24 months of CI use). The deaf children were recruited from the Otorhinolaryngology Research Center of AmirAlam Hospital and 8 Rehabilitation Centers in Tehran. The normal group included 48 normally developed children ages 12-24 months. Their scores on all developmental domains (communication, fine motor, gross motor, personal, social and problem solving skills) on the Age \& Stage Questionnaire (ASQ) [Vameghi et al., 2013) were within normal limits. The children had no history of physical damage, seizures, brain damage, or any other disorders. The typically developed children were recruited from 22 kindergartens supervised by the Welfare Organization in Tehran. The parents who signed the consent form filled out the ASQ and the checklist. The verbal \& non-verbal communication screening checklist for Persian-speaking children aged 12-24 months, that is a valid and reliable instrument to screen the communicative abilities in 12 to 18 month- old toddlers (Safariyan et al., 2017) were used as well. The verbal \& non-verbal communication screening checklist was composed of two sections: the first section was for 12 to 18 month- old children and the second section was developed for children between the ages of 18 to 24 months. Each section was divided to two categories: verbal communication (expressive language, receptive language and speech) and non-verbal communication. The questions required a yes/no response from parent or caregiver. The examiner calculated the number of "yes" responses as the: total score, and total scores of expressive language, receptive lan- 
guage and non-verbal communication, separately.

This study was approved by the Ethics Committee of the Iran University of Medical Sciences. The participants were allowed to withdraw from the study at any stage.

Statistical analysis was conducted using SPSS21. The descriptive statistics and non-parametric testing (the Mann-Whitney U) were conducted. Statistical significance level was set at $\mathrm{P}$ value $<0.05$.

\section{Results}

The participants in current study were divided into two groups. Table 1 represents the descriptive statistics (mean and SD) of the children's chronological age.

Table 2 shows the verbal and non-verbal communica- tion scores in 5 subgroups: The deaf children without CI aged 12-24 months, the children with unilateral CI after 12-18 months of CI use, the children with unilateral CIs after 18-24 months of CI use, The normal hearing children aged 12-18 months and children aged 18-24 months. A Kolmogorov-Smirnov test at $P>0.05$ was conducted, which indicated that the data were not normally distributed; hence, a Mann-Whitney $U$ test was used to compare the mean scores.

The results showed significant difference between the total scores achieved by deaf children without CI, and children with $\mathrm{CI}$ and normal children $(P<0.0001)$; however, there was no difference between normal group and children with $\mathrm{CI}(P=0.841, P=0.450)$.

Table 1. Descriptive statistics of children's chronological age in both control and case groups $(n=87)$

\begin{tabular}{|c|c|c|c|}
\hline \multicolumn{4}{|c|}{ Chronological Age } \\
\hline Groups & Subgroups & Mean & SD \\
\hline \multirow{2}{*}{ Normal } & Aged $12-18$ months & 15.81 & 1.28 \\
\hline & Aged 18-24 months & 20.56 & 1.5 \\
\hline \multirow{3}{*}{ Deaf } & $\begin{array}{c}\text { With CI } \\
12-18 \text { months after CI use }\end{array}$ & 42.46 & 11.78 \\
\hline & $\begin{array}{c}\text { With CI } \\
18-24 \text { months after CI use }\end{array}$ & 53.75 & 15.59 \\
\hline & $\begin{array}{c}\text { Without CI } \\
\text { Aged } 12-24 \text { months }\end{array}$ & 17 & 4.31 \\
\hline
\end{tabular}

Table 2. Descriptive statistics for the total scores of verbal \& non-verbal communication screening checklist $(n=87)$

\begin{tabular}{|c|c|c|c|}
\hline \multicolumn{4}{|c|}{ Total scores } \\
\hline Groups & Subgroups & Mean & SD \\
\hline \multirow{2}{*}{ Normal } & Aged $12-18$ months & 23.57 & 2.46 \\
\hline & Aged 18-24 months & 26.44 & 2.88 \\
\hline \multirow{3}{*}{ Deaf } & $\begin{array}{c}\text { With CI } \\
12-18 \text { months after CI use }\end{array}$ & 21.85 & 5.3 \\
\hline & $\begin{array}{c}\text { With CI } \\
18-24 \text { months after CI use }\end{array}$ & 25.50 & 4.4 \\
\hline & $\begin{array}{c}\text { Without CI } \\
\text { Aged } 12-24 \text { months }\end{array}$ & 11.50 & 3.73 \\
\hline
\end{tabular}


The mean scores of the verbal communication (expressive and receptive languages) and non-verbal communication were calculated in each subgroup, separately (Table 3). Based on the results, no significant difference was observed between normal children and children with CI on mean scores of expressive and receptive languages and non-verbal communication. Moreover, normal children had significantly higher expressive and receptive language scores than children without CI (Table 3). However, this pattern was not observed in the non-verbal communication abilities. In other words, all four groups exhibited statistically similar results in the non-verbal communication subtest of the questionnaire (Table 3 ).

Table 3. Descriptive statistics for the scores of verbal (receptive and expressive language) and non-verbal communication ( $n=87$ )

\begin{tabular}{|c|c|c|c|c|}
\hline & & \multicolumn{2}{|c|}{ Verbal Communication } & \multirow{2}{*}{ Non-Verbal Communication } \\
\hline & & Receptive Language & Expressive Language & \\
\hline Groups & Subgroups & Mean(SD) & Mean(SD) & Mean(SD) \\
\hline \multirow{2}{*}{ Normal } & Aged 12- 18 months & $4.95(0.21)$ & $9.95(1.24)$ & $8.81(1.4)$ \\
\hline & Aged 18-24 months & $7.37(0.68)$ & $9.70(2.31)$ & $9.44(2.31)$ \\
\hline \multirow{3}{*}{ Deaf } & $\begin{array}{c}\text { Children with CI } \\
\text { 12-18 months after CI use }\end{array}$ & $4.62(0.76)$ & $8.31(3.32)$ & $8.92(2.29)$ \\
\hline & $\begin{array}{c}\text { Children with CI } \\
\text { 18-24 months after CI use }\end{array}$ & $7.17(1.03)$ & $9.50(3.03)$ & $8.83(1.26)$ \\
\hline & $\begin{array}{c}\text { Without CI } \\
\text { Aged } 12-24 \text { months }\end{array}$ & $2.07(1.43)$ & $1.01(1.38)$ & $7.36(3.69)$ \\
\hline
\end{tabular}

\section{Discussion}

There is a sensitive period in the brain development process that affects the brain. It includes language acquisition which is completed around puberty (Knudsen, 2004; Horford, 1991). Sharma et al. believed that the sensitive period of the human central auditory system is about 3.5 years and in some children remains until the age of 7 years (Sharma et al., 2002).

Recent studies have proved that early implantation has more positive effects on the language outcomes compared to the late implantation. Several factors have been reported to be effective on the acquisition of oral language skills, among which age is the most influential one (Peterson et al., 2010). Geers and Nicholas recommended early implantation during 12 to 36 months (Geers and Nicholas, 2013), since children who got the implant under 24 months of age, showed more improvements in spoken language abilities than those who got the implant later (Nicholas and Geers, 2007; Niparko et al., 2010; Holt, 2004). However, cochlear implant is also beneficial for older children, but the degree of improvement decreases by age of implantation. In other words, more spoken language achievement is observed in children receiving $\mathrm{CI}$ at the age of 2-5 years comparing to those who receive it after the age of 5 years (Fryauf-Bertschy et al, 1997; Wang et al., 2007). Koşaner et al. concluded that children who got the implant between 24 to 60 months of age tend to develop language skills similar to those who were implanted before the age 24 months (Koşaner et al., 2017).

In the current study, the mean age of deaf children showed that they had no implant before 2 years old. Do the language skills of children after 12-24 months using CI get close to those skills of the children at the age of 12-24 months? In order to find the answer, we used the verbal \& non-verbal communication screening checklist. Parents could describe and explain about their child's communication skills and provide reliable information for the researchers. Therefore, investigators can explore different aspects of language skills in children through the questionnaires.

The parents filled out the checklist about the verbal and non-verbal communicative abilities of their 
children. The results showed that the verbal communication (expressive and receptive) abilities of deaf children after 12-18 months of using CI were similar to the normal children at the age of 12-18 months. Similarly, the verbal communication abilities of deaf children after 18-24 months of using CI, reached to the skills of normal children at the age of 18-24 months (Appendix A). The deaf children without CI did not have the verbal communication abilities like the normal children at the age of 12-18 months. However, non-verbal communication was similar to their peers. For instance, they could express their intention by referring to it, they could shake and nod their head for the yes/no response and they had normal pointing gesture and joint attention.

Therefore, it can be concluded that spoken language acquisition is the consequence of the CI. Even when $\mathrm{CI}$ is conducted after the age of 2 years, it can significantly help to develop the verbal abilities in deaf children.

\section{References}

Archbold, S., Harris, M., O’Donoghue, G., Nikolopoulos, T., White, A., \& Richmond, H. L. (2008). Reading abilities after cochlear implantation: The effect of age at implantation on outcomes at 5 and 7 years after implantation. International journal of pediatric otorhinolaryngology, 72(10), 1471-1478.

Budenz, C.L., Telian, S.A., Arnedt, C., Starr, K., Arts, H.A., El- Kashlan, H.K., \& Zwolan, T.A. (2013). Outcomes of cochlear implantation in children with isolated auditory neuropathy versus cochlear hearing loss. Otology and Neurotology , 34(3),477- 483.

Dale, P.S.(1991). The validity of a parent report measure of vocabulary and syntax at 24 months. Journal of Speech, Language, and Hearing Research, 34(3), 565-71.

Fryauf-Bertschy, H.L., Tyler, R.S., Kelsay, D.M., Gantz, B.J., Woodworth, G.G.(1997). Cochlear implant use by prelingually deafened children: the influences of age at implant and length of device use. Journal of Speech, Language, and Hearing Research, 99-183,(1), 40 .

Geers, A.E., Nicholas, J.G. (2013). Enduring Advantag-

\section{Conclusion}

The verbal \& non-verbal communication screening checklist for Persian-speaking children aged 12-24 months was evaluated. It seems that children with CI can acquire the oral communication ability at least at the level of 12-24-month-old children. It can be expected that deaf children who receive CI late, will reach the verbal communication abilities of 12-24-month-old typically children, about 12 to 24 months post-implantation.

\section{Acknowledgements}

This work was supported by vice-chancellor for research, Iran University of Medical Sciences [fund number 94-05-32-27301]. The authors are grateful to the parents of the children who participated in this study.

\section{Conflict of Interest Statement}

Authors declared no conflict of interest.

es of Early Cochlear Implantation for Spoken Language Development . Journal of Speech, Language, and Hearing Research, 56(2), 643-655.

Holt, R., Svirsky, M.A., Neuberger, H., Miyamoto, R.T. (2004). Age at implantation and communicative outcome in pediatric cochlear implant users: Is younger always better? International Congress Series 1273, 368-71. 5.

Holt, R.F., and Svirsky, M.A. (2008). An exploratory look at pediatric cochlear implantation: is earliest always best? Ear and Hearing, 29(4):492-511.

Horford, J.R. (1991).The evolution of the critical period for language acquisition. Cognition. 40(3),159-201.

Huttunen., K. Välimaa, T. (2010) Parents' Views on Changes in Their Child's Communication and Linguistic and Socioemotional Development After Cochlear Implantation. Journal of Deaf Studies and Deaf Education, 15 (4), 383-404.

Knudsen, E.I. (2004). Sensitive Periods in the development of the brain and behavior. Journal of Cognitive Neuroscience, 16,1412-1425.

Koşaner, J., Deniz, H., Uruk, D., Deniz, M., Kara, E. , Amann, E.(2017). Assessment of early language devel- 
opment in Turkish children with a cochlear implant using the TEDIL test. Cochlear Implants International, 3 (18), 153-161.

Kumar, P., Sanju, H. K., Mishra, R., Singh, V., \& Mohan, P. (2017). Parental Expectation from Children with Cochlear Implants in Indian Context: a Questionnaire Based Study. International archives of otorhinolaryngology, 21(2), 156-160.

Kumar, S., Rout, N., Kumar, N., Chatterjee, I., \& Selvakumaran, H. (2013). Performance of Indian children with cochlear implant on PEACH scale. ISRN otolaryngology, 2013.

May-Mederake, B. (2012). Determining early speech development in children with cochlear implants using the ELFRA-2 parental questionnaire. International journal of pediatric otorhinolaryngology, 76(6), 797-801.

Nicholas, J. G., \& Geers, A. E. (2007). Will they catch up? The role of age at cochlear implantation in the spoken language development of children with severe to profound hearing loss. Journal of speech, language, and hearing research.

Nikolopoulos, T. P., Lloyd, H., Archbold, S., \& O'donoghue, G. M. (2001). Pediatric cochlear implantation: the parents' perspective. Archives of Otolaryngology-Head \& Neck Surgery, 127(4), 363-367.

Niparko, J. K., Tobey, E.A., Thal, D.J., Eisenberg, L.S., Wang, N-Y., Quittner, A.L., Fink, N.E.(2010). the CDaCI Investigative Team. Spoken language development in children following cochlear implantation. Journal of the American Medical Association. 303, 1498-1506.

Peterson, N.R. , Pisonia, D.B., Miyamoto, R.T.(2010). Cochlear implants and spoken language processing abilities: Review and assessment of the literature. Restorative Neurology and Neuroscience, 28(2), 237-250.

Robins, A.M., Svirsky, M., Kirk, K.L.(1997). Children with implant can speak, but can they communicate? Otolaryngology-Head and Neck Surgery, 117, 155-60.

Safariyan, N., Jalilevand, N., Kamali, M., Ebrahimipour, M., \& Mehri, A. (2017). The Verbal \& Non-Verbal Communication Screening Checklist for Persian Speaking Children From 12 to 24 Months and Its Validity and Reliability. Iranian Rehabilitation Journal, 15(1), 71-76.
Sharma, A., Dorman, M.F., Spahr, A.J. (2002).A sensitive period for the development of the central auditory system in children with cochlear implants: implications for age of implantation. Ear and Hearing, 23, 532-539.

Vameghi, R., Sajedi, F., Mojembari, A. K., Habiollahi, A., Lornezhad, H. R., \& Delavar, B. (2013). Cross-cultural adaptation, validation and standardization of Ages and Stages Questionnaire (ASQ) in Iranian children. Iranian journal of public health, 42(5), 522.

Wang, N.M., Huang, T.S., Wu, C.M., Kirk, K.I.(2007). Pediatric cochlear implantation in Taiwan: Long - term communication out comes. International journal of pediatric otorhinolaryngology, 71(11),1775-82.

Wetherby, A., Prizant, B., Meisels, S. J., \& Fenichel, E. (1996). Toward earlier identification of communication and language problems in infants and young children. New visions for the developmental assessment of infants and young children, 289-312. 


$$
\text { مقالة يزوهشى }
$$

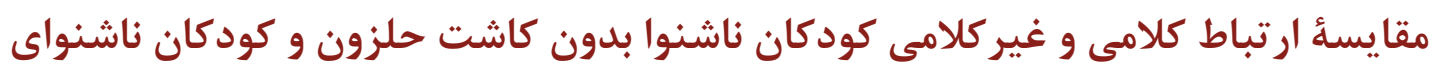

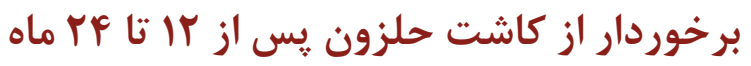

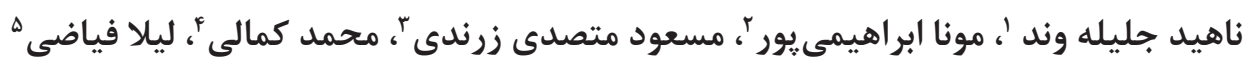

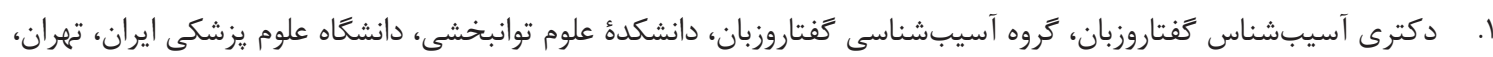

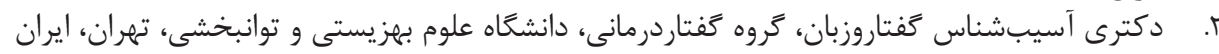

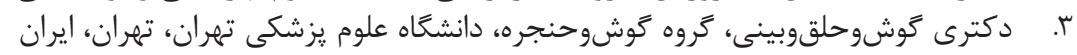

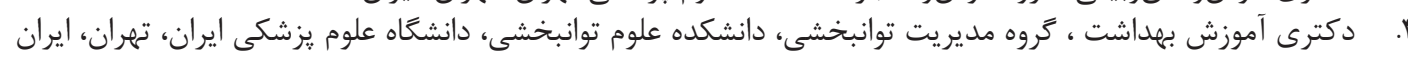

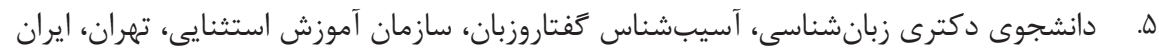

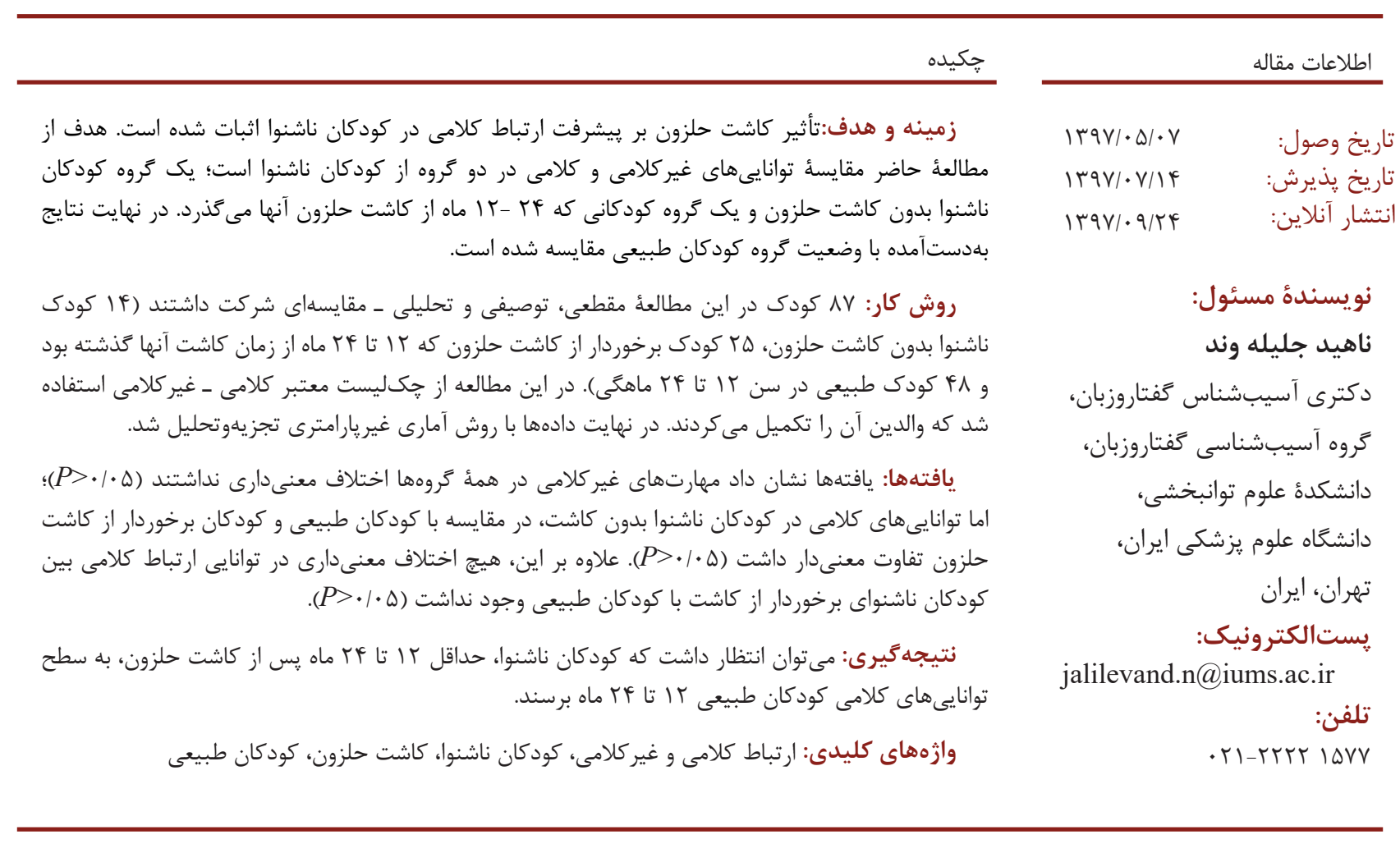

